\title{
Staged percutaneous coronary intervention and minimally invasive valve surgery: Results of a hybrid approach to concomitant coronary and valvular disease
}

\author{
Orlando Santana, MD, ${ }^{\mathrm{a}}$ Michael Funk, MD, ${ }^{\mathrm{a}}$ Carlos Zamora, MD, ${ }^{\mathrm{a}}$ Esteban Escolar, MD, ${ }^{\mathrm{a}}$ \\ Gervasio A. Lamas, $\mathrm{MD},{ }^{\mathrm{a}}$ and Joseph Lamelas, $\mathrm{MD}^{\mathrm{b}}$
}

\begin{abstract}
Background: We compared a hybrid approach combining staged percutaneous coronary intervention (PCI) and minimally invasive valve surgery with concurrent valve surgery plus bypass via a median sternotomy approach.

Methods: We retrospectively evaluated 65 consecutive patients with coronary disease and surgical valvular heart disease who underwent planned PCI followed within 60 days by minimally invasive valve surgery, and we compared them with 52 matched control patients who underwent conventional bypass grafting and valve surgery.

Results: There were no in-hospital deaths in the hybrid group, compared with $2(3.8 \%)$ observed in the matched group $(P=.11)$. Death, renal failure, or stroke occurred in $1(1.5 \%)$ in the hybrid group versus $15(28.8 \%)$ in the conventional group $(P=.001)$. The median number of days between PCI and surgery was 24 (interquartile range, 2.5-37). At surgery, 23 hybrid patients were receiving both aspirin and clopidogrel; , 18, clopidogrel alone; 4 , aspirin alone; and 22 stopped the antiplatelet agents 5 days before the operation. Intensive care unit hours and total hospital length of stay, including PCI stay for the hybrid group, were less in the hybrid group $(P=.001$ for both comparisons). In the hybrid group, average blood use was $1.6 \pm 1.6 \mathrm{U}$ per patient versus $1.9 \pm 2.4 \mathrm{U}$ per patient with conventional surgery $(P=.35$. There were no reoperations for postoperative bleeding in the hybrid group compared with $2(3.8 \%)$ in the conventional group $(P=.43)$.
\end{abstract}

Conclusions: Staged PCI with minimally invasive valve surgery may offer an alternative to coronary bypass grafting with concurrent valve surgery and should be tested prospectively. (J Thorac Cardiovasc Surg 2012;144:634-9)

Coronary artery bypass graft (CABG) with concomitant valve surgery has a higher mortality than does isolated valve surgery or isolated CABG. ${ }^{1-3}$ Typically, patients are sicker, operative times are longer, and morbidity and mortality are increased. Thus, some groups have begun exploring a strategy to dissociate the procedures into 2 smaller, staged procedures-minimally invasive valve surgery and percutaneous coronary intervention (PCI). When compared with a standard median sternotomy approach, the potential benefits of minimally invasive valve surgery include less trauma and faster recovery time, possibly leading to improved outcomes. ${ }^{4-14}$ Inasmuch as PCI has a mortality of less than $1 \%$ in elective settings and minimally invasive valve procedures have a mortality between $0.7 \%$ and $2 \%,{ }^{15,16}$ a hybrid approach that

From the Columbia University Division of Cardiology ${ }^{\mathrm{a}}$ and the Division of Cardiac Surgery $^{\mathrm{b}}$ at the Mount Sinai Heart Institute, Miami Beach, Fla.

Disclosures: Authors have nothing to disclose with regard to commercial support.

Received for publication Aug 5, 2011; revisions received Sept 27, 2011; accepted for publication Nov 7, 2011; available ahead of print Dec 12, 2011.

Address for reprints: Orlando Santana, MD, Director, Echocardiography Laboratory, Columbia University Division of Cardiology, Mount Sinai Heart Institute, $4300 \mathrm{Al}$ ton Rd, Miami Beach, FL 33140 (E-mail: osantana@msmc.com).

$0022-5223 / \$ 36.00$

Copyright (c) 2012 by The American Association for Thoracic Surgery doi:10.1016/j.jtcvs.2011.11.008 combines PCI with minimally invasive valve surgery is worthy of consideration. ${ }^{16-20}$ We report our experience using this staged method in a nonrandomized, but consecutive, case series.

\section{METHODS}

After obtaining approval from the institutional review board, we retrospectively reviewed the medical records of 65 consecutive patients with concomitant coronary and valvular disease who underwent staged PCI followed, within 60 days, by minimally invasive valve surgery between February 2009 and June 2011. Their outcomes were compared with a matched control group of 52 patients who underwent simultaneous conventional CABG and valve surgery, necessarily by median sternotomy, between March 2005 and June 2011. Excluded were patients who underwent aortic root replacement, had active endocarditis, had left main coronary artery disease, or underwent emergency surgery. All median sternotomy operations were performed by a group of 6 surgeons. All minimally invasive operations were performed by 1 of the 6 surgeons. The median sternotomy control group was matched on the basis of decade age, number of diseased coronary vessels, gender, creatinine level, type of valve surgery, and heart failure. The definitions and variables selected were based on The Society of Thoracic Surgeons Database definitions. Composite surgical complications were defined as the presence of postoperative renal failure, stroke, myocardial infarction, or death. The hybrid patients were evaluated in the outpatient setting 30 days after the operation.

\section{Patient Selection}

In all patients the coronary and valvular lesions were documented by diagnostic catheterization and echocardiography. The patients were selected 


\section{Abbreviations and Acronyms \\ $\mathrm{CABG}=$ coronary artery bypass grafting \\ $\mathrm{IQR}=$ interquartile range \\ $\mathrm{PCI}=$ percutaneous coronary intervention}

to undergo a staged approach at the discretion of the referring cardiologist and/or by the surgeon.

\section{Procedural Staging}

Once the treatment plan was established, the interventional cardiologist proceeded with PCI and possible stent placement of the coronary artery lesion or lesions. In all patients receiving stents, a loading dose of $600 \mathrm{mg}$ of clopidogrel and $325 \mathrm{mg}$ of aspirin was administered at the time of stent placement, followed by clopidogrel $75 \mathrm{mg} /$ day and aspirin $325 \mathrm{mg} /$ day thereafter. Management of antiplatelet therapy between the PCI and the operation was at the discretion of the interventional cardiologist.

\section{Technique for Minimally Invasive Valve Surgery}

All patients were placed in the supine position and underwent anesthetic induction and intubation with a single-lumen endotracheal tube and a bronchial blocker. A roll was placed underneath the right scapula in patients undergoing a minimally invasive mitral valve procedure. Every patient had a Swan-Ganz catheter (Edwards LifeSciences, Irvine, Calif) and a radial arterial line placed. A transesophageal echocardiogram Doppler probe was placed intraoperatively to evaluate the diseased valves, as well as to assess the postoperative results.

In all cases except 1 , a femoral platform was used to establish cardiopulmonary bypass. A 2- to 3-cm incision was made in the inguinal crease. A 5-0 Prolene polypropylene purse-string suture (Ethicon, Inc, Somerville, $\mathrm{NJ})$ was placed on the femoral artery and vein. After heparinization, a Seldinger technique was used to cannulate the femoral vessels. The femoral artery was cannulated with a $16 \mathrm{~F}$ to $18 \mathrm{~F}$ arterial cannula (Edwards Lifesciences), and the femoral vein. Transesophageal echocardiography was used to aid in placement of the venous cannula in the superior vena cava.

For the mitral valve procedures, a 4- to 5-cm skin incision was made in the fourth to fifth intercostal space at the site of the anterior axillary line. The same incision was made for patients having double valve surgery involving the mitral and tricuspid valves. For the mitral valve repair and replacements, the mitral valve was accessed through the Waterston groove and then through the atrial septum into the left atrium. A specially designed atrial lift retractor and atrial exposure device was used for visualization of the mitral valve. Mitral valve repair or replacement was carried out in the standard fashion. A 4-0 Prolene polypropylene suture was used to close the left atrium.

In the patients undergoing mitral valve surgery with a history of CABG, we used moderate-to-deep hypothermia $\left(24^{\circ} \mathrm{C}-26^{\circ} \mathrm{C}\right)$ and fibrillatory arrest. Cardioplegic solution was not delivered at all. Air was removed via a vent placed through the atriotomy, mitral valve, and into the left ventricle. If significant peripheral vascular disease was present in patients undergoing mitral valve procedures, then axillary artery cannulation was performed, as was the case in 1 patient of our study.

For aortic valve procedures, a 4- to 5-cm transverse parasternal incision was made over the second to third intercostal space. This incision was extended to 6 to $7 \mathrm{~cm}$ in those undergoing combined aortic and mitral valve surgery. In all aortic valve procedures, the second or third costochondral cartilage was transected to allow adequate exposure of the aorta. At the completion of the operation, the rib was reattached to the sternum with a 1-cm metal plate (Synthes, West Chester, Pa) and a fiber wire was placed in a figure-of- 8 fashion. In all cases, the pericardium was opened above the phrenic nerve and over the aorta to facilitate exposure. A transverse aortotomy was performed for exposure of the aortic valve. Valve replacement was carried out under direct vision by standard techniques. In aortic valve procedures, a left ventricular vent was inserted into the left ventricle via a purse-string suture in the right superior pulmonary vein.

In patients undergoing aortic valve replacement who have a previous CABG and a patent left internal thoracic graft, we use moderate hypothermia $\left(28^{\circ} \mathrm{C}\right)$ with one induction dose of antegrade cardioplegic solution. Thereafter, cardioplegic solution is delivered retrogradely at 20-minute intervals. We do not dissect the left internal thoracic artery pedicle. In the setting of a patent left internal thoracic artery, we prefer the native left anterior descending artery to be totally occluded. This diminishes a constant stream of blood return from the left main coronary artery obscuring the operative field. If the left anterior descending artery is patent, we place a No. 10F red rubber catheter, connected to a pump suction, into the left main coronary artery to aspirate the blood. If significant peripheral vascular disease had been present, then central aortic cannulation would have been performed, but this was not the case in any of the patients.

With transesophageal echocardiography guidance, a retrograde coronary sinus catheter was directly inserted through the incision, and a purse-string suture was placed in the right atrium. Cardiopulmonary bypass was initiated at $32^{\circ} \mathrm{C}$ to $36^{\circ} \mathrm{C}$ using a closed membrane oxygenator and roller pump. Venous drainage was augmented with vacuum assistance applying negative pressures of 30 to $70 \mathrm{~mm} \mathrm{Hg}$ as needed to decompress the right side of the heart. Transincisional direct aortic crossclamping was performed with a flexible and retractable shaft crossclamp (Novare Surgical Systems, Cupertino, Calif). One dose of antegrade cold blood cardioplegia was given to establish electromechanical arrest of the heart. Thereafter, retrograde cold blood cardioplegia was given throughout the procedure at 20- to 25-minute intervals. If retrograde cardioplegia was not possible, a cannula was left in the ascending aorta to deliver antegrade cardioplegia, or the heart was fibrillated. All procedures were performed with specially designed long-shafted minimally invasive instruments (Geister, Tuttlingen, Germany). Carbon dioxide was infused into the operative field during the entire procedure. Air was removed from the heart with a needle in the root of the aorta and under transesophageal echocardiographic guidance. The heart was not directly manipulated during deairing maneuvers. If needed, external compression of the chest wall was performed to aid in deairing. With the heart empty, both atrial and ventricular pacing wires were placed. After cardiopulmonary bypass had been discontinued and protamine administered, decannulation was performed. The purse-string sutures were tied, and the femoral artery was directly repaired with 5-0 Prolene polypropylene suture. A single chest tube was left in the pleural space. For pain relief, all patients had an On-Q pain relief system inserted (I-Flow Corporation, Lake Forest, Calif). Two catheters were placed in the intercostal space to deliver $0.25 \%$ bupivicaine for 72 hours. The thoracotomy incision was closed in the routine fashion.

\section{Statistical Analysis}

All continuous variables are expressed as the means \pm 1 standard deviation. Nonparametric variables were expressed as medians and interquartile ranges (IQRs, or $25 \%$ to $75 \%$ ). An independent $t$ test was used to compare continuous variables between groups that had a normal distribution. Nonparametric variables were compared with a Mann-Whitney $U$ test. All dichotomous variables were compared by $\chi^{2}$ analysis. The statistical analyses were done using SPSS version 17 (SPSS, Inc, Chicago, Ill).

\section{RESULTS}

From February 2009 to June 2011, 65 patients underwent staged PCI followed by elective minimally invasive valve surgery. There were $37(57 \%)$ men and $28(43 \%)$ women with a mean age of $75.4 \pm 8$ years. The baseline 
TABLE 1. Patient baseline characteristics

\begin{tabular}{|c|c|c|c|}
\hline Variables & $\begin{array}{l}\text { Hybrid } \\
\text { group } \\
(n=65)\end{array}$ & $\begin{array}{c}\text { Conventional } \\
\text { group } \\
(\mathbf{n}=\mathbf{5 2})\end{array}$ & $\begin{array}{c}P \\
\text { value }\end{array}$ \\
\hline \multicolumn{4}{|l|}{ Variables } \\
\hline Age (mean $\pm 1 \mathrm{SD})$ & $75.4 \pm 8$ & $73.8 \pm 8.2$ & .3 \\
\hline Gender (male) & $37(57 \%)$ & $29(55 \%)$ & .9 \\
\hline $\mathrm{EF}($ mean $\pm 1 \mathrm{SD})$ & $53.9 \pm 12.5 \%$ & $50 \pm 12.6 \%$ & .036 \\
\hline Prior MI & $19(29 \%)$ & $11(21.2 \%)$ & .32 \\
\hline $\mathrm{BMI}($ mean $\pm 1 \mathrm{SD})$ & $27.8 \pm 4.6$ & $27.2 \pm 4.5$ & .46 \\
\hline Diabetes mellitus & $25(38 \%)$ & $15(28.8 \%)$ & .28 \\
\hline Hypertension & $55(85 \%)$ & $49(94 \%)$ & .1 \\
\hline COPD & $16(25 \%)$ & $16(30.8 \%)$ & .46 \\
\hline $\mathrm{CHF}$ & $24(37 \%)$ & $26(50 \%)$ & .15 \\
\hline CVA & $11(17 \%)$ & $5(9.6 \%)$ & .25 \\
\hline $\begin{array}{l}\text { Preoperative creatinine level } \\
\quad(\text { mean } \pm 1 \mathrm{SD})\end{array}$ & $1.21 \pm 1.1$ & $1.16 \pm 0.49$ & .56 \\
\hline Previous CABG surgery & 5 & 1 & .16 \\
\hline Previous AVR & 2 & 0 & .06 \\
\hline EuroSCORE (mean $\pm 1 \mathrm{SD})$ & $10 \pm 8.45 \%$ & $8.9 \pm 4.84 \%$ & .7 \\
\hline \multicolumn{4}{|l|}{ Preoperative medications } \\
\hline Aspirin & $43 \%$ & $44 \%$ & .7 \\
\hline Clopidogrel & $64 \%$ & $17 \%$ & $<.001$ \\
\hline ACE inhibitors/ARB & $67 \%$ & $42 \%$ & .00 \\
\hline Nitrates & $5 \%$ & $7 \%$ & .76 \\
\hline Beta-blockers & $67 \%$ & $73 \%$ & .24 \\
\hline Statins & $71 \%$ & $64 \%$ & .49 \\
\hline Warfarin & $10 \%$ & $23 \%$ & .04 \\
\hline
\end{tabular}

$S D$, Standard deviation; $E F$, ejection fraction; $M I$, myocardial infarction; $B M I$, body mass index; $C O P D$, chronic obstructive pulmonary disease; $C H F$, congestive heart failure; $C V A$, cerebrovascular accident; $C A B G$, coronary artery bypass grafting; $A V R$, aortic valve replacement; $A C E$, agtiotensin converting enzyme; $A R B$, angiotensin II receptor blocker.

characteristics were similar between the hybrid and conventional groups, with the exception that the ejection fraction was slightly lower in the conventional group $(53.9 \% \pm$ $12.5 \%$ vs $50 \% \pm 12.6 \% ; P=.036)$ and there were more patients with a history of cardiac surgery in the hybrid group than in the conventional group (7 [10.7\%] vs $1[1.9 \%]$, although the difference did not reach statistical significance; $P=.06)$. The EuroSCORE predicted operative mortality was $10 \% \pm 8.45 \%$ and $8.9 \% \pm 4.84 \%$ for the hybrid and the conventional groups, respectively $(P=.7$; Table 1). There was also no significant difference in the number of diseased vessels of the hybrid group versus the conventional group (Table 2).

All hybrid patients were clinically stable for both PCI and surgery, except for 2 patients whose PCI was

TABLE 2. Comparison of the number of diseased vessels between the hybrid and the conventional group

\begin{tabular}{lccc}
\hline $\begin{array}{c}\text { No. of diseased } \\
\text { vessels }\end{array}$ & $\begin{array}{c}\text { Hybrid group } \\
(\mathbf{n}=\mathbf{6 5})\end{array}$ & $\begin{array}{c}\text { Conventional group } \\
(\mathbf{n}=\mathbf{5 2})\end{array}$ & $\boldsymbol{P}$ value \\
\hline 1 & $36(55.3 \%)$ & $29(42 \%)$ & .56 \\
2 & $15(23.1 \%)$ & $29(42 \%)$ & .48 \\
3 & $14(21.5 \%)$ & $11(16 \%)$ & .96 \\
\hline
\end{tabular}

TABLE 3. Antiplatelet therapy of hybrid patients at time of cardiac valve surgery

\begin{tabular}{lc}
\hline & $\mathbf{N}=\mathbf{6 5}(\%)$ \\
\hline Antiplatelet agents stopped 5 days before surgery & $20(30.7 \%)$ \\
Aspirin alone & $4(6.1 \%)$ \\
Clopidogrel alone & $18(27.7 \%)$ \\
Aspirin and clopidogrel & $123(35.4 \%)$ \\
Any clopidogrel & $41(63 \%)$ \\
\hline
\end{tabular}

performed in the setting of an ST-elevation myocardial infarction and underwent minimally invasive surgery electively later. Of the 7 patients with a history of cardiac surgery, 5 had previous $C A B G$ and underwent mitral valve repair for severe functional mitral regurgitation and 2 had a history of aortic valve replacement with $\mathrm{CABG}$ and now had severe paravalvular aortic insufficiency needing repeat aortic valve replacement.

\section{Description of PCI}

In the hybrid arm, $36(55.3 \%)$ patients underwent 1-vessel, $15(23.1 \%)$ underwent 2-vessel, and 14 (21.5\%) underwent 3-vessel PCI. Drug-eluting stents were placed in $36(55.5 \%)$, bare metal stents in $25(38.5 \%)$, and balloon angioplasty was performed in $4(6.2 \%)$. The anatomic locations of the lesions treated with PCI were as follows: 21 $(32.3 \%)$ proximal left anterior descending coronary artery, $40(61.5 \%)$ mid-left anterior descending coronary artery, $26(40 \%)$ right coronary artery, and $21(32.3 \%)$ circumflex coronary artery. There were 2 post-PCI procedural complications. A femoral arteriovenous fistula, which needed repair, developed in 1 patient, and a groin infection, which was treated with antibiotics, developed in the other. The median number of days between PCI and surgery was 24 (IQR, 2.5-37).

\section{Description of Surgery}

At the time of surgery in the hybrid group, 23 (35.4\%) patients were receiving both aspirin and clopidogrel, 18 $(27.7 \%)$ were taking clopidogrel alone, $4(6.1 \%)$ were taking aspirin alone, and $20(30.7 \%)$ patients had their antiplatelet agents stopped 5 days before surgery (Table 3). All patients were placed on their preoperative anticoagulation regimen on day 1 or 2 postoperatively. The type of valve surgery performed was not significantly different between the 2 groups, except that there were $10(15.3 \%)$ double valve operations in the hybrid group and none in the conventional group, with the difference in the numbers of aortic valve replacements with mitral valve repairs reaching statistical significance $(P=.025$; Table 4$)$.

In the hybrid group, of the 31 patients who had aortic valve replacement, $29(93.5 \%)$ were operated on for severe aortic stenosis and $2(6.4 \%)$ for prosthetic aortic valve regurgitation. Of the 24 patients who had mitral valve surgery, 
TABLE 4. Type of valve surgery performed

\begin{tabular}{lccc}
\hline & $\begin{array}{c}\text { Hybrid } \\
(\mathbf{n = 6 5})\end{array}$ & $\begin{array}{c}\text { Conventional } \\
(\mathbf{n = 5 2})\end{array}$ & $\begin{array}{c}\boldsymbol{P} \\
\text { value }\end{array}$ \\
\hline Aortic valve replacement alone & $31(47.7 \%)$ & $32(61.5 \%)$ & .14 \\
Mitral valve repair alone & $14(21.5 \%)$ & $14(28.8 \%)$ & .37 \\
Mitral valve replacement alone & $10(15.4 \%)$ & $5(9.6 \%)$ & .36 \\
Aortic valve replacement plus & $6(9.2 \%)$ & 0 & .025 \\
$\quad$ mitral valve repair & & & \\
$\begin{array}{c}\text { Aortic valve replacement plus } \\
\text { mitral valve replacement }\end{array}$ & $4(6.2 \%)$ & 0 & .07 \\
\hline
\end{tabular}

$13(54.1 \%)$ had functional mitral regurgitation, 6 (25\%) had myxomatous degeneration, and $5(20.8 \%)$ had regurgitation. The 10 patients who had aortic valve replacement with mitral valve repair or replacement consisted of patients with severe aortic stenosis, 6 of whom had mitral regurgitation owing to calcific degeneration of the mitral valve and 4 , functional mitral regurgitation.

The median aortic crossclamp and cardiopulmonary bypass times for the hybrid group were 84.5 minutes (IQR, 71-108) and 115 minutes (IQR, 96-135), respectively; for the conventional group they were 64 minutes (IQR, 4792) and 95 minutes (IQR, 78-115), $P=.001$ and $P=.004$, respectively.

\section{Clinical Outcomes}

There were no deaths in the hybrid group, whereas the inhospital mortality for the conventional group was $2(3.8 \%$; $P=.11)$. Of the 2 patients who died in the conventional group, 1 did so from pneumonia/sepsis and the other died of acute renal failure that was followed by an acute myocardial infarction. Composite postoperative complications (renal failure, stroke, myocardial infarction, or death) occurred significantly less frequently in the hybrid group than in the control group: $1(1.5 \%)$ versus $16(30.8 \%)(P=.001)$. The incidence of prolonged intubation was $7(10.7 \%)$ in the hybrid group and $22(42.3 \%)$ in the median sternotomy group $(P<.001)$. The mean number of packed red blood cells transfused in the hybrid group was $1.6 \pm 1.6$ units and in the conventional group, $1.9 \pm 2.4$ units $(P=.35)$. There was $1(1.5 \%)$ reoperation for postoperative bleeding in the hybrid arm compared with 2 in the conventional group $(P=.43)($ Table 5).

In the hybrid group, there were 41 patients taking clopidogrel at the time of surgery and 24 who were not. Those receiving clopidogrel required a mean of $1.9 \pm 1.8$ units of transfused packed red blood cells, whereas those not receiving clopidogrel required a mean of $1.4 \pm 1.5$ units $(P=.36)$.

\section{Resource Use}

The median length of stay in the intensive care unit was 50 hours (IQR, 38-92) for the hybrid group and 98 hours
TABLE 5. Operative results

\begin{tabular}{|c|c|c|c|}
\hline Variables & $\begin{array}{l}\text { Hybrid } \\
\text { group } \\
(n=65)\end{array}$ & $\begin{array}{c}\text { Conventional } \\
\text { group } \\
(\mathbf{n}=\mathbf{5 2})\end{array}$ & $\begin{array}{c}P \\
\text { value }\end{array}$ \\
\hline In-hospital mortality & 0 & $2(3.8 \%)$ & .11 \\
\hline Composite complications & $1(1.5 \%)$ & $16(38.8 \%)$ & .001 \\
\hline $\begin{array}{l}\text { ICU length of stay (h, median, } \\
\text { IQR) }\end{array}$ & $50(38-92)$ & $98(66-138)$ & .001 \\
\hline $\begin{array}{l}\text { Length of hospital stay } \\
\text { (d, median, IQR) }\end{array}$ & $9(7-12)$ & $15(10-20)$ & .001 \\
\hline $\begin{array}{l}\text { Units of PRBCs transfused } \\
\qquad(\text { mean } \pm 1 \mathrm{SD})\end{array}$ & $1.6 \pm 1.6$ & $1.9 \pm 2.4$ & .35 \\
\hline $\begin{array}{l}\text { Aortic crossclamp time } \\
(\mathrm{min}, \text { median, } \mathrm{IQR})\end{array}$ & $84.5(71-108)$ & $64(47-92)$ & .001 \\
\hline CPB time (min, median, IQR) & $115(96-135)$ & $95(78-115)$ & .004 \\
\hline Prolonged ventilation & $7(10.7 \%)$ & $22(42.3 \%)$ & $<.001$ \\
\hline Postoperative renal failure & $1(1.5 \%)$ & $9(17.3 \%)$ & .002 \\
\hline $\begin{array}{l}\text { Bleeding requiring } \\
\text { reoperation }\end{array}$ & $1(1.5 \%)$ & $2(3.8 \%)$ & .43 \\
\hline Postoperative CVA & 0 & $2(3.8 \%)$ & .11 \\
\hline
\end{tabular}

Composite complications: mortality, renal failure, myocardial infarction, and cerebrovascular accidents. Hybrid group hospital length of stay includes the length of stay for the percutaneous coronary intervention. $I C U$, Intensive care unit; $I Q R$, interquartile range; $P R B C s$, packed red blood cells; $S D$, standard deviation; $C P B$, cardiopulmonary bypass; $C V A$, cerebrovascular accident.

(IQR, 66-138) for the control group $(P=.001)$. The total length of hospital stay, which included the hospital days for the PCI interventions, was shorter in the hybrid group, with a median of 9 days (IQR, 7-12) versus 15 days (IQR, 10-20) for the control group $(P=.001)$.

\section{DISCUSSION}

A hybrid procedure that changes a conventional $\mathrm{CABG}$ with concurrent valve surgery into a PCI with isolated minimally invasive valve surgery is an appealing way to parse and minimize the risk of complex heart surgery. Our report of a consecutive series of patients undergoing staged PCI and minimally invasive valve surgery demonstrates a low cumulative complication rate for the hybrid approach, coupled with a short length of intensive care unit and overall hospital stay. Indeed, a comparison with matched historical controls at the same institution demonstrated the superiority of the hybrid approach.

This hybrid approach was first evaluated by Byrne and colleagues ${ }^{16}$ in a study of 26 patients with acute coronary syndrome who underwent PCI followed by valve surgery within a median of 5 days. The operative mortality was $3.8 \%$, which was much lower than the $22 \%$ mortality predicted by the Society of Thoracic Surgeons Database. Because of the use of dual antiplatelet therapy, a high incidence of bleeding occurred, with $22(85 \%)$ of the 26 patients requiring blood transfusions. In an attempt to reduce the incidence of bleeding, Brinster and colleagues ${ }^{20}$ performed the PCI the day of, or evening before, the scheduled 
minimally invasive aortic valve replacement in 18 patients. There were no reoperations for bleeding, and only 8 (44\%) patients required blood transfusions. The hybrid patients in our study had a lower number of blood transfusions than the conventional group, but the difference did not reach statistical significance. However, our study differs from the previously mentioned studies in that we had a significant variation on the use of antiplatelet agents, which is a reflection of the different practice patterns among the interventional cardiologists. We noted no difference in the need for blood transfusions between the patients taking clopidogrel and those who were not taking it. On the basis of our preliminary results, we recommend continuing dual antiplatelet agents on the hybrid patients when they undergo minimally invasive valve surgery. The current guidelines for antiplatelet management in patients with a bare metal coronary stent who require surgery within 6 weeks of stent placement is to continue aspirin and clopidogrel in the perioperative period, as well as in those who have had a drugeluding stent who require surgery within 12 months of stent placement. ${ }^{21}$

As more hybrid $\mathrm{PCI} / \mathrm{valve}$ procedures are being performed, many questions remain unanswered, including the optimal order for the procedures, their timing, the management of dual antiplatelet therapy, and the optimal costs and logistics of the procedures. ${ }^{22}$ It would be reasonable to hypothesize that the 1-stop approach proposed by Brinster and colleagues ${ }^{20}$ not only reduces bleeding but also is more convenient for the patient and more cost effective than a 2-stage approach. This approach requires a high degree of coordination between the interventional cardiologist and the cardiothoracic surgeon, which may be facilitated by the presence of a "hybrid" operating room designed for performing both procedures. ${ }^{22}$ However, our experience suggests that a hybrid approach combining PCI with minimally invasive valve surgery can be done safely without these special rooms.

Given the trends toward increases in minimally invasive cardiac surgery, the broad applicability of the hybrid approach described here may be particularly appealing. Gammie and colleagues ${ }^{23}$ reported that from 2004 to 2008 the percentage of mitral valve operations that were done via a minimally invasive approach increased from $11.9 \%$ to $20.1 \%(P<.0001)$. With this progression, it is most likely that a hybrid approach will increase as well. On the other hand, the short-term benefits of a hybrid approach are not without potential long-term hazards. Clinical trials suggest that, in many instances, full revascularization with coronary surgery may be superior to partial revascularization with PCI. Moreover, the long-term intervention-free survival of a left internal thoracic graft to the left anterior descending coronary artery is probably superior to the best currently available drug-eluting stent. Thus, the results of this shortterm, single-center study should be viewed as supporting a prospective randomized controlled clinical trial to compare a hybrid (staged) PCI and minimally invasive valve surgery with the conventional median sternotomy approach.

\section{Study Limitations}

This was a single-center, retrospective study of a heterogeneous group of patients. All minimally invasive operations were performed by a single surgeon (J.L.). Selection of patients for PCI was based on favorable anatomy for this procedure, which is an important selection bias. The follow-up of the patients was limited to 30 days, and thus no statement may be made regarding long-term differences in outcomes, as might be expected when comparing PCI and CABG. Also, the control group and the study cohort were not concurrent in terms of the time frames of the procedures performed. The length of hospital stay in the conventional patients was high at 15 days, which reflected patient recovery times and clinical practice. These are uncontrollable confounders, and in view of this, the results can only be interpreted as hypothesis-generating.

\section{CONCLUSIONS}

In selected sites with a surgical team comfortable with minimally invasive surgery, a staged approach of PCI followed by minimally invasive valve surgery may be an effective approach for selected patients with suitable coronary and valvular anatomy.

\section{References}

1. Hannan EL, Wu C, Bennett EV, Carlson RE, Culliford AT, Gold JP, et al. Risk index for predicting in-hospital mortality for cardiac valve surgery. Ann Thorac Surg. 2007;83:921-9.

2. Thourani VH, Weintraub WS, Craver JM, Jones EL, Gott JP, Brown WM III, et al. Influence of concomitant CABG and urgent/emergent status on mitral valve replacement surgery. Ann Thorac Surg. 2000;70:778-83.

3. Society of Thoracic Surgeons: Executive summary: STS report ending 12/31/ 2011. Available at http://www.sts.org/national-database/database-managers/ executive-summaries.

4. Cohn LH, Adams DH, Couper GS, Bichell DP, Rosborough DM, Sears SP, et al. Minimally invasive cardiac valve surgery improves patient satisfaction while reducing costs of cardiac valve replacement and repair. Ann Surg. 1997;226:421-6.

5. Estrera AL, Reardon MJ. Current approaches to minimally invasive aortic valve surgery. Curr Opin Cardiol. 2000;15:91-5.

6. Mihaljevic T, Cohn LH, Unic D, Aranki SF, Couper GS, Byrne JG. One thousand minimally invasive valve operations: early and late results. Ann Surg. 2005;240: 529-34.

7. Doll N, Borger MA, Hain J, Bucerius J, Walther T, Gummert JF, et al. Minimal access aortic valve replacement: effects on morbidity and resource utilization. Ann Thorac Surg. 2002;74:S1318-22.

8. Raja SG, Navaratnarajah M. Impact of minimal access valve surgery on clinical outcomes: current best available evidence. J Card Surg. 2009;24:73-9.

9. Bakir I, Casselman FP, Wellens F, Jeanmart H, De Geest R, Degrieck I, et al. Minimally invasive versus standard approach aortic valve replacement: a study in 506 patients. Ann Thorac Surg. 2006;81:1599-604.

10. Scarci M, Young C, Fallou H. Is ministernotomy superior to conventional approach for aortic valve replacement? Interact Cardiovasc Thorac Surg. 2009;9: 314-7.

11. Modi P, Hassan A, Chitwood WR Jr. Minimally invasive mitral valve surgery: a systematic review and meta-analysis. Eur J Cardiothorac Surg. 2008;34:943-52.

12. Lamelas J, Sarria A, Santana O, Pineda AM, Lamas GA. Outcomes of minimally invasive valve surgery versus median sternotomy in patients 75 years or greater. Ann Thorac Surg. 2011;91:75-80. 
13. Santana O, Reyna J, Grana R, Buendia M, Lamas GA, Lamelas J. Outcomes of minimally invasive valve surgery versus standard sternotomy in obese patients undergoing isolated valve surgery. Ann Thorac Surg. 2011;91:406-10.

14. Mihos CG, Santana O, Lamas GA, Lamelas J. Outcomes of right minithoracotomy mitral valve surgery in patients with previous sternotomy. Ann Thorac Surg. 2011;91:1824-8.

15. Soltesz EG, Cohn LH. Minimally invasive valve surgery. Cardiol Rev. 2007;15: 109-15.

16. Byrne JG, Leacche M, Unic D, Rawn JD, Simon DI, Rogers CD, et al. Staged initial percutaneous coronary intervention followed by valve surgery ("hybrid approach") for patients with complex coronary and valve disease. JAm Coll Cardiol. 2005;45:14-8.

17. Loulmet D, Carpentier A, d'Attellis N, Berrebi A, Cardon C, Ponzio O, et al. Endoscopic coronary artery bypass grafting with the aid of robotic assisted instruments. J Thorac Cardiovasc Surg. 1999;118:4-10.

18. Angelini GD, Wilde P, Salerno TA, Bosco G, Calafiore AM. Integrated left small thoracotomy and angioplasty for multivessel coronary artery revascularization. Lancet. 1996;347:757-8
19. Greelish JP, Ailiwadi M, Balaguer JM, Ahmad RM, Zhao DX, Petracek MR et al. Combined percutaneous coronary intervention and valve surgery. Curr Opin Cardiol. 2006;21:113-7.

20. Brinster DR, Byrne M, Rogers CD, Baim DS, Simon DI, Couper GS et al. Effectiveness of same day percutaneous coronary intervention followed by minimally invasive aortic valve replacement for aortic stenosis and moderate coronary disease ("hybrid approach"). Am J Cardiol. 2006;98:1501-3.

21. Douketis JD, Berger PB, Dunn AS, Jaffer AK, Spyropoulos AC, Becker RC, et al The perioperative management of antithrombotic therapy. American College of Chest Physicians evidence-based clinical practice guidelines (8th edition). Chest. 2008;133:299-339S

22. Byrne JG, Leacche M, Vaughan DE, Zhao DX. Hybrid cardiovascular procedures. J JACC Cardiovasc Interv. 2008;1:459-68.

23. Gammie JS, Zhao Y, Peterson ED, O’Brien SM, Rankin JS, Griffith BP. Less-in vasive mitral valve operations: trends and outcomes from The Society of Thoracic Surgeons Adult Cardiac Surgery Database. Ann Thorac Surg. 2010;90: 1401-10. 